\title{
Undergraduate Programme: Admissions for 2013
}

The Indian Institute of Science, a leading institution of higher learning with a strong tradition of research, offers a four-year Bachelor of Science (B.S.) Programme which is designed as a balanced blend of core science and interdisciplinary topics to serve as a platform for attractive career opportunities in academia and industry. Applications are invited for admission to the four-year B S programme at the Institute. Eligibility, selection criteria and other details are available at our website http://www.iisc.ernet.in/ug

\section{ELIGIBILITY}

Candidates who have completed their II PUC / 12th Standard in 2012 and those who are expecting to complete their II PUC / 12th Standard in 2013 are eligible to apply. The candidates must have studied Physics, Chemistry and Mathematics as main subjects during their II PUC / 12th Standard. Candidates who have studied Biology, Statistics, Electronics, Computer Science, etc., in addition to Physics, Chemistry and Mathematics are also eligible to apply. The candidates must have secured a first class or $60 \%$ or equivalent grade (relaxed to pass class for SC/ ST candidates) in the II PUC / 12th Standard examination.

\section{SELECTION}

Based on the merit list of one of the following national examinations: KVPY-SA [appeared in 2011 and selected for the Fellowship], KVPY-SB [appeared in 2012 and selected for the Fellowship], KVPY-SX [appeared in 2012 and selected for the Fellowship], KVPY Fellows selected through the Empowerment Initiative for SC/ST candidates, IIT-JEE-Main [appearing in 2013 and securing a minimum of $60 \%$ (GN), 54\% (OBC-NCL), 30\% (SC/ $\mathrm{ST} / \mathrm{PH}$ )], IIT-JEE-Advanced [appearing in 2013 and securing a minimum of $60 \%$ (GN), 54\% (OBC-NCL), 30\% (SC/ST/PH)], and NEET-UG [appearing in 2013 and getting selected in the main merit list].

Reservation for SC/ST/OBC/Physically-Handicapped (PH) and Kashmiri-Migrant (KM) candidates: As per Government of India regulations.

\section{HOW TO APPLY}

(a) Application Forms (available only online): The online application may be prepared and submitted by accessing the IISc website www.iisc.ernet.in/ug with effect from 01.02.2013. The application fee is Rs. 400/- for GN/OBC/ $\mathrm{KM}$ candidates and Rs. 200/- for SC/ST/PH categories.

(b) Payment of the Application Fee: Mode of payment options available are: (1) Online Payment - Net-banking, Visa Card/ Master Card, Debit/Credit Cards. (2) Offline Payment - SBI/Canara Bank branches accept Challan payment across the country. The bank service charge is extra (to be borne by the applicants).

IMPORTANT DATES

Commencement of submission of online applications $\quad \mathbf{0 1 . 0 2 . 2 0 1 3}$

Last date for submission of online applications

30.04.2013 